\title{
A Study of Vocabulary Learning Strategies Among Undergraduate Learners of A.M.U.
}

\author{
Sadaf Zarrin, Zoya Khan \\ Aligarh Muslim University, Aligarh, India
}

\begin{abstract}
One of the most important challenges that learners face during the process of second language learning is learning vocabulary. Vocabulary has been recognized as crucial to language use in which insufficient vocabulary knowledge of the learners lead to difficulties in second language learning. Thus, in the case of learning vocabulary in second language, students need to be educated with VLS (vocabulary learning strategies). For this study, we used Schmitt's (1997) classification of VLS that are classified as determination, social, memory, cognitive, and meta-cognitive strategies. The main purpose of this paper is to examine and investigate the use of current vocabulary teaching and learning strategies among undergraduate learners at A.M.U. (Aligarh Muslim University). The paper first reviews the problems encountered by learners in learning language due to lack of vocabulary. It then discusses some common VLS. Based on the aim of this study, it was decided that the best method for this investigation to better understand the use of VLS by these particular students is to adopt the quantitative research design. The present study, by the use of questionnaire has investigated the second language vocabulary learning situation among 46 under-graduates in terms of their perspective of vocabulary learning, strategy use. Furthermore, statistical analysis of the data revealed that memory strategy was found as the most frequently used strategy whereas metacognitive strategy as the least frequently one. It indicated that the participants of the current study need more training on VLS to become more familiar with all types of VLS. Effective vocabulary learning and teaching strategies need to be incorporated into learners’ vocabulary learning process.
\end{abstract}

Keywords: VLS (vocabulary learning strategies), Schmitt’s (1997) classification of VLS, ELT (English language teaching) pedagogy

\section{Introduction}

In learning a foreign or second language, vocabulary plays an important role. It is such an element as links the four skills of listening, speaking, reading, and writing all together. Despite being crucial to language use, it has never got the recognition and status. Even though learners have realized the significance of vocabulary while learning language, most of them learn vocabulary passively. Language learners have nothing to do in vocabulary learning, but to listen to their teachers, etc.

This nonchalant attitude towards vocabulary learning has been the cause of difficulty witnessed among

Sadaf Zarrin, Ph.D., Department of English, Aligarh Muslim University.

Zoya Khan, Ph.D., Department of English, Aligarh Muslim University. 
learners to find the right words to express their thoughts. McCarthy (2001, as cited in FAN, 2003) explained that vocabulary develops the main component of any language, and vocabulary is the major issue nearly all learners. Thus, one of the most challenges that learners face during the process of second/foreign language learning is acquiring vocabulary.

According to Laufer (2003), most of the learners match English words with their equivalents in the first language. They also focus on literal meaning of single words, and do not learn the meaning of the words from the given context. Because of this, it is difficult for them to comprehend a reading text while they are familiar with the meanings of the words in it. The next problem is that students are not able to use the words with their proper collocates, for example, a beautiful man instead of a handsome man. It shows that many students have a limited range of vocabulary and this problem will affect their comprehension when producing the language. As Allen (1983) emphasized that "lexical problems frequently interfere with communication; communication breaks down when people do not use the right words” (p. 5).

This is due to the unawareness of the students with VLS (vocabulary learning strategies). Learners can increase their word power, awareness, and understanding of the words by VLS. This process will increase their success in learning English. In addition, not much has been done regarding teaching and learning vocabulary in an actual Indian classroom context and an explicit guideline on how vocabulary is learned efficiently is still lacking.

\section{Objectives of the Study}

The main purpose of the current study is to investigate the use of VLS by undergraduate students in A.M.U. (Aligarh Muslim University). Thus, the following research objectives can be mentioned: (1) to explore VLS used by under-graduate learners; (2) to identify the level of undergraduate learners in terms of VLS use in A.M.U.; and (3) to explore the most and least frequently used VLS among Undergraduate Learners in A.M.U..

\section{Research Questions}

According to the above research objectives, the following research questions will be addressed: (1) What VLS are employed by undergraduate students in learning English vocabulary?; (2) Are A.M.U. undergraduate students, high, medium, or low strategy users?; and (3) What are the most and least frequently used VLS of A.M.U. learners?.

\section{VLS}

Vocabulary is one of the basic elements which are crucially important for learning a second or foreign language. Although language learners are familiar with the significance of words in a language, they are generally unaware with VLS that make vocabulary learning easier. Sokmen (1997, p. 225) argued that for students to learn all the vocabulary they need in the classroom is impossible. Thus, he was in a favor of helping learners learn how to acquire vocabulary on their own. As Cunningsworth (1995) thought of helping learners to develop their own VLS as "a powerful approach" (p. 38), which can be based on sensitization to the systems of vocabulary, encouragement of sound dictionary skills, and reflection on effective learning techniques. Second language acquisition strongly depends on the development of a powerful vocabulary. "Any techniques or tools 
which can be used to learn vocabularies quickly, easily and independently are called vocabulary learning strategy" (Kafipour, Yazdi, Soori, \& Shokrpour, 2011, p. 65). According to GU (1994), particular strategies used by second language learners for the acquisition of new words in the second language are called "VLS". The importance of learners' independence in vocabulary learning has long been accepted by a number of linguists. In view of Gairns and Redman (1986), after elementary level, it is difficult for teachers to select vocabulary that may fulfill the needs of all individuals; hence, it is no use to spend time on it. On the contrary, student should be more responsible for their learning. Oxford and Scarcella (1994) were in the support of providing systematic vocabulary instruction to let learner master specific strategies to learn words even outside their classrooms. For Nation $(1990,2001)$, the most important way to build vocabulary is learners using strategies independently of a teacher. According to N. Schmitt and D. Schmitt (1995), the best teaching plan may be to present different kinds of learning strategies to students so that they themselves may choose the best suitable ones to them. Moreover, Nation (2001) also suggested that VLS enables learners to take the responsibility for their own learning. He supposed that a large amount of vocabulary can be learnt by using VLS. By definition, vocabulary learning is the process, in which information is obtained, stored, retrieved and used (Rubin, 1981).

A number of scholars have attempted to classify learning strategies such as O’Malley and Chamot (1990) put forwarded three types of strategies: metacognitive, cognitive, and social/affective strategies. Oxford (1990) proposed two broad categories of strategies namely, direct and indirect strategies. The former strategy includes memory, cognitive, and compensation strategies while the latter one includes metacognitive, affective, and social strategies. Also GU and Johnson (1996) presented two main dimensions of VLS for their study: metacognitive regulation and cognitive strategies which deal with six subcategories namely, guessing, using a dictionary, note taking, rehearsal, encoding, and activating. The total number of strategies in their study was 74 items. There are different vocabulary strategies classification systems; however, the classification introduced by Schmitt (2000) is the basis for the current study. He organized 58 categories into five types. According to this classification, strategies are classified as determination, social, memory, cognitive, and metacognitive.

(1) Determination strategies: These strategies are used by learners "to discover the meaning of new words without other's help” (Schmitt, 2000). Learners determine the meaning of unfamiliar words by using reference materials like dictionaries; guessing the meaning from the textual context; and identifying the parts of speech and constituent elements.

(2) Social strategies: They are used to determine the word definitions by asking teachers, classmates and native speakers. In short, it involves interaction with each other and learning from each other (Schmitt, 2000). They can also be used to make information stable by speaking to native speakers or even language teachers outside the class.

(3) Memory strategies: Memory strategies traditionally known as Mnemonics, help learners to acquire the new words by connecting new words to the background knowledge (Schmitt, 2000), using some form of imagery or grouping (grouping words with collocation, i.e., idea—great, brilliant, unusual, and original). They can aid in the retention of new words. Memory strategies are made up of three groups: (a) Using images to 
make a strong connection with the word and its meaning. These images can be developed in the mind or drawn in notebooks, (b) Using strategies to connect words together in such a way to bring vocabulary back. For example, using words in the sentences to make retrieval easier, and (c) Using vocabulary knowledge aspects to stabilize the meaning of the new words. Some examples are, paying attention to the word's phonological or orthographical form, memorizing affixes and roots, matching some words to their corresponding physical action, and learning the word class.

(4) Cognitive strategies: They deal with mechanical aspects of learning vocabulary and are not related to mental processing (Schmitt, 2000). The most commonly used cognitive strategies are repetition, taking notes and highlighting new words, making lists of new words, using flashcards to record new words, put English labels on physical objects, keeping a vocabulary notebooks, and writing the words many times.

(5) Metacognitive strategies: These strategies represent learners' capability to find opportunities for learning and then record and review those experiences. In other words, metacognitive strategies include monitoring, decision-making, and assessment of one’s advance (Kafipour \& Naveh, 2011, p. 618). They can also help learners to specify suitable VLS for learning new words (Schmitt, 2000). Specific examples include using English language media, studying new words many times, paying attention to English words when someone is speaking English, continuing to study new words over times, and skipping or passing new words.

\section{Recent Studies of L2 VLS}

GU and Johnson (1996) investigated the VLS used by 850 non-English major at a university in China, also explored their vocabulary size and language proficiency. They correlated the result of each investigation. According to Schmitt (1997) survey among 600 Japanese students, dictionary, and repetition strategies were considered the more useful strategies than any other. SHEN (2003) provided a 2C-5R model for effectively teaching and learning vocabulary. Whereas, the study of Kafipour and Naveh (2011) showed how positively VLS contributed to reading comprehension.

\section{Research Methodology}

\section{Participants}

This study is done among 46 undergraduate learners at A.M.U. in India. They are randomly selected for this study.

\section{Instruments}

For the current study data have been collected by administering Schmitt's VLSQ (Vocabulary Learning Strategies Questionnaire) adapted from Bennett (2006). It was a 41 items likert-scale questionnaire with reliability coefficient of 0.73 obtained by Kafipour and Naveh (2011). But we have taken only 21 items for this study which were suitable for exploration of the problem.

\section{Procedures}

A group of subjects were identified from undergraduate course. Questionnaires were administered in a group after giving them proper instructions. A rapport was formed before distributing questionnaire and subjects were assured about confidentiality. No specific time has been assigned. 


\section{Statistical Analysis}

In order to get the result data were analyzed using SPSS (Statistical Package for Social Science) version 16. Descriptive statistics (mean and standard deviation) are used to answer research questions. The correlation has also been identified among different VLS.

\section{Results and Discussion of Findings}

The analyzed data have been summarized here through three different tables. On the basis of descriptive statistics, Tables1-2 have been reproduced. Table 1 shows the overall strategy used by the learners with mean of 64.89 indicating they are medium strategy users.

Table 1

Overall Strategy Use $(N=46)$

\begin{tabular}{ll}
\hline Mean & Std. deviation \\
\hline 64.89 & 10.84 \\
\hline
\end{tabular}

Table 2 clearly depicts that memory strategy has been determined the most frequently used strategies by the learners with mean score ( $M=14.97)$, and metacognitive, the least frequent, having the mean score $(M=7.47)$. Social $(M=14.58)$, cognitive $(M=14.56)$, and determination $(M=13.28)$ are ordered as 2,3 , and 4 rank respectively in terms of their uses. It also clears that learners are somehow familiar with first four strategies as mentioned in Table 2, except with the fifth one, i.e., metacognitive strategy.

Table 2

Descriptive Statistics: Mean, Standard Deviation, and Rank Order $(N=46)$

\begin{tabular}{lllll}
\hline Strategy & Mean & Std. Deviation & Rank & Strategy use \\
\hline Memory & 14.97 & 3.27 & 1 & Medium \\
Social & 14.58 & 3.22 & 2 & Medium \\
Cognitive & 14.56 & 4.52 & 3 & Medium \\
Determination & 13.28 & 2.41 & 4 & Medium \\
Meta cognitive & 7.47 & 2.21 & 5 & Lower \\
\hline
\end{tabular}

Table 3

Correlations Among the VLS $(N=46)$

\begin{tabular}{|c|c|c|c|c|c|}
\hline Strategies & 1 & 2 & 3 & 4 & 5 \\
\hline \multicolumn{6}{|l|}{ Memory } \\
\hline Social & 0.274 & & & & \\
\hline Cognitive & $0.0514^{* *}$ & $0.489 * *$ & & & \\
\hline Determination & $0.469 * *$ & $0.34 *$ & $0.411 * *$ & & \\
\hline Metacognitive & $0.365^{*}$ & -0.021 & 0.092 & $0.37 *$ & \\
\hline
\end{tabular}

Notes. ${ }^{*} p<0.05 ; * * p<0.01$.

Table 3 reveals that there is positive significant correlation of memory strategy with cognitive strategy $(r=0.514, p<0.01)$, determination $(r=0.469, p<0.01)$, and metacognitive $(r=0.365, p<0.05)$ which implies that memory strategy is used as much as cognitive, determinative, and metacognitive strategies. It is also depicted here that social strategy is positively and significantly correlated with cognitive strategy $(r=0.489$, 
$p<0.01)$, and determination strategy $(r=0.34, p<0.05)$ which infers that the social strategy users used cognitive and determination strategy as well. It is shown here also, cognitive strategy is positively correlated with only determination strategy $(r=0.411, p<0.01$ ) that suggests the one who uses cognitive strategy must use determination strategy and vice versa. It is described through the above table that there is positive significant correlation of determination strategy only with metacognitive strategy $(r=0.37, p<0.05)$ which indicates that determination strategy users are more users of metacognitive strategy. This analysis is basically done to identify the interrelationship among these strategies.

\section{Conclusions}

To summarize, we can say that the undergraduate learners at A.M.U. are more familiar with memory, social, and cognitive strategies, whereas determination and metacognitive strategies are less introduced to them. From the mean score of the overall response of learners, we have investigated that they are medium strategy users for learning vocabulary. Oxford (1990) suggested that using a strategy at a medium level shows the learners are aware of the strategies but they need to be encouraged to use them more in their learning process. Our study also implies that these learners use memory strategy most frequently, as they think it more convenient for vocabulary learning. When they encounter with any new word, they first associate it with the words that they are already familiar with or make strong bond with an image to its meaning. The results of correlation table seem us as researchers, that all strategies are more or less interrelated with each other. Metacognitive strategy is the least used-strategies. We must acknowledge here that our study had a limitation as it covered a limited number of students for study, which may challenge the generalization. But it paved the way for further research in this direction in special context to A.M.U..

\section{Implication and Recommendation}

Some practical implications and recommendation of our study are as follows.

Learners as well as teachers can be benefitted from this survey. Learners have been asked to respond for use of 21 effective language learning strategies. So, this survey makes them aware of many of the strategies that they never tried and also encourage them to try the listed strategies to memorize or retrieve vocabulary. The learners' levels in terms of using VLS also come into the knowledge of the teacher. They may teach these techniques to their students during vocabulary enhancing classroom as per the learners' needs and their suitability. From the results of the study, it can be recommended that proper training for using of VLS is in need to make them efficient and independent lexical learners.

\section{References}

Allen, V. F. (1983). Techniques in teaching vocabulary. Oxford: Oxford University Press.

Bennett, P. (2006). An evaluation of vocabulary teaching in an intensive study programme (Unpublished M.A. thesis, University of Bermingham, Bermingham, United Kingdom).

Cunningsworth, A. (1995). Choosing your coursebook. Oxford: Heinemann.

FAN, Y. M. (2003). Frequency of use, perceived usefulness, and actual usefulness of second language vocabulary strategies: A study of Hong Kong learners. The Modern Language Journal, 87(2), 222-241.

Gairns, R., \& Redman. S. (1986). Working with words: A guide to teaching and learning vocabulary. Cambridge: Cambridge University Press. 
GU, P. Y. (1994). Vocabulary learning strategies of good and poor Chinese EFL learners (p. 27). The Twenty-Eighth Annual Convention and Exposition, Baltimore.

GU, Y., \& Johnson, R. K. (1996). Vocabulary learning strategies and language learning outcomes. Language Learning, 46(4), 643-679.

Kafipour, R., \& Naveh, M. H. (2011). Vocabulary learning strategies and their contribution to reading comprehension of EFL undergraduate students in Kerman province. European Journal of Humanities and Social Sciences, 23(4), 614-635.

Kafipour, R., Yazdi, M., Soori, A., \& Shokrpour, N. (2011). Vocabulary levels and vocabulary learning strategies of Iranian undergraduate students. Studies in Literature and Language, 3(3), 64-71.

Laufer, B. (2003). Vocabulary acquisition in a second language: Do learners really acquire most vocabulary by reading? Some empirical evidence. Applied Linguistics, 19, 255-271.

Nation, I. S. P. (1990). Teaching and learning vocabulary. Boston: Newbury House.

Nation, I. S. P. (2001). Learning vocabulary in another language. Cambridge: Cambridge University Press.

O’Malley, J., \& Chamot, A. (1990). Learning strategies in second language acquisition. Cambridge: Cambridge University.

Oxford, R. (1990). Language learning strategies: What every teacher should know. Boston: Newbury House.

Oxford, R. L., \& Scarcella, R. C. (1994). Second language vocabulary learning among adults: State of the art in vocabulary instruction. System, 22 (2), 231-243.

Rubin, J. (1981). Study of cognitive processes in second language learning. Applied Linguistics, 11, 117-131.

Schmitt, N. (1997). Vocabulary learning strategies. In N. Schmitt, \& M. McCarthy (Eds.), Vocabulary: Description, acquisition and pedagogy (pp. 199- 227). Cambridge: Cambridge University Press.

Schmitt, N. (2000). Vocabulary in language teaching. New York: Cambridge University Press.

Schmitt, N., \& Schmitt, D. (1995). Vocabulary notebooks: Theoretical underpinnings and practical suggestions. ELT Journal, 49, 133-243.

SHEN, W. (2003). Current trends of vocabulary teaching and learning strategies for EFL setting. Feng Chia Journal of Humanities and Social Sciences, 7, 187-224.

Sokmen, A. (1997). Current trends in teaching second language vocabulary. In N. Schmitt, \& M. McCarthy (Eds.), Vocabulary: Description, acquisition and pedagogy (pp. 237-257). Cambridge: Cambridge University.

\section{Appendix: Questionnaire}

Dear respondent,

I shall be very grateful for your response to this questionnaire. The information given will be used only for research purpose and will be kept confidential.

Before answering the questionnaire, please read instructions very carefully.

(1) There is no true and false answer.

(2) Tick the strategy that you really use, not the one you think to be the best.

(3) Answer one by one without looking at the following.

(4) Finally, thank you for your sincere cooperation.

\begin{tabular}{|l|l|l|l|l|l|l|}
\hline & When you find a new English word, you... & Never & Seldom & Sometimes & Often & Always \\
\hline$(1)$ & Infer the meanings of words from textual context. & & & & & \\
\hline$(2)$ & $\begin{array}{l}\text { Use an English-English dictionary or English- Mother Tongue } \\
\text { dictionary. }\end{array}$ & & & & & \\
\hline$(3)$ & $\begin{array}{l}\text { Analyze affixes and roots to guess the meanings of words (e.g., } \\
\text { reconsider, re- means do it again). }\end{array}$ & & & & & \\
\hline$(4)$ & Check new word's form (verb, noun, adjective etc.). & & & & & \\
\hline$(5)$ & Discover the meaning through group activities. & & & & \\
\hline$(6)$ & $\begin{array}{l}\text { Ask the teacher to translate the meaning of a word that you do } \\
\text { not understand. }\end{array}$ & & & & & \\
\hline$(7)$ & Ask the teacher for synonyms and antonyms of new words. & & & & & \\
\hline$(8)$ & Ask your classmates for meaning. & & & & & \\
\hline$(9)$ & Infer meaning through images and pictures that describe it. & & & & & \\
\hline$(10)$ & Study the sound and spelling of that word. & & & & & \\
\hline
\end{tabular}




\begin{tabular}{|l|l|l|l|l|l|l|}
\hline & $\begin{array}{l}\text { When you want to remember new words and build your } \\
\text { vocabulary, you... }\end{array}$ & Never & Seldom & Sometimes & Often & Always \\
\hline$(11)$ & $\begin{array}{l}\text { Use images to create a strong connection with the word and its } \\
\text { meaning. }\end{array}$ & & & & & \\
\hline$(12)$ & List vocabulary alphabetically to review. & Never & Seldom & Sometimes & Often & Always \\
\hline & When you find a new English word, you... & & & & & \\
\hline$(13)$ & Learn the word through verbal repetition. & & & & & \\
\hline$(14)$ & Associate the word with words that you already know. & & & & & \\
\hline$(15)$ & Write the words many times. & & & & & \\
\hline$(16)$ & Ask the teacher to create a sentence by using that new word. & & & & \\
\hline$(17)$ & Keep a vocabulary notebook wherever you go. & & & & & \\
\hline$(18)$ & Use flash cards to retrieve. & & & & \\
\hline$(19)$ & $\begin{array}{l}\text { Pay attention to English words when someone is speaking } \\
\text { English. }\end{array}$ & & & & & \\
\hline$(20)$ & Use English-language media (songs, movies, the Internet). & & & & \\
\hline$(21)$ & Test yourself with word tests. & & & & \\
\hline
\end{tabular}

